\title{
QUANDO NÚMEROS VIRAM DESENHOS: ESTRATÉGIAS DE RESOLUÇÃO DE PROBLEMAS POR CRIANÇAS DO $1^{\circ}$ ANO
}

\author{
WHEN NUMBERS BECOME DRAWINGS: PROBLEMS SOLVING \\ STRATEGIES BY CHILDREN IN THE 1ST YEAR OF ELEMENTARY SCHOOL \\ THIARLA XAVIER DAL-CIN ZANON ${ }^{1}$ \\ VÂNIA MARIA PEREIRA DOS SANTOS-WAGNER ${ }^{2}$
}

\section{RESUMO}

Neste artigo, procedeu-se à análise do desenho de três crianças do $1^{\circ}$ ano do ensino fundamental, quando resolveram um problema de contagem com solução apresentada por uma estratégia que demandava uma cena ilustrada. Os dados advêm de um estudo qualitativo do tipo pesquisa-ação desenvolvido em 2011. Nele, há evidências de percepções acerca da matemática identificada no desenho dos estudantes a partir do que haviam entendido da história. A interpretação do enunciado do problema proposto pela professora iniciante e a resposta dos estudantes a ele mostraram 0 que as crianças escutaram e entenderam da tarefa oral que deveriam resolver por meio do desenho. É notório 0 efeito do problema formulado pela professora que, ao propô-lo, pensava focalizar apenas aritmética. Por isso, o texto traz algumas implicações desta tarefa para os leitores, pois acredita-se que professores e pesquisadores possam investigar cuidadosamente o potencial de tarefas similares quando alunos resolvem variados problemas de matemática.

Palavras-chave: Problema de contagem. Desenho de crianças do $1^{0}$ ano. Interpretação do enunciado. Matemática.

\section{ABSTRACT}

In this article, we analyzed drawings done by three children in the 1st year of elementary school, when they solved a counting problem with a solution presented through a strategy that demanded an illustrated scene. The data come from a qualitative study using an action research developed in 2011. In it, there is evidence of perceptions about the mathematics identified in the drawing by children in relation to what they had understood about the story. The interpretation of the problem statement proposed by the beginning teacher and the students' response to it showed what the children heard and understood about the oral task that they should solve through drawing. The effect of the problem formulated by the teacher, who, when proposing it, thought to focus only on arithmetic, is notorious. Therefore, the text brings some implications of this task for readers, as it believes that teachers and researchers can carefully investigate the potential of similar tasks when students solve various mathematics problems.

Keywords: Counting problem. Drawing done by children in the 1st year of elementary school. Interpretation of problem text. Mathematics.

\section{RESUMEN}

En este artículo, pasamos al análisis del dibujo de tres niños del primer año de la escuela primaria, cuando resolvieron un problema de conteo com solución presentada por medio de una estrategia que exigía una escena ilustrada. Los datos provienen de un estudio cualitativo del tipo de investigación-acción desarrollado en 2011. En él, hay evidencia

1 Doutora em Educação pela Universidade Federal do Espírito Santo (UFES). Professora do Instituto Federal do Espírito Santo (IFES) campus Cachoeiro de Itapemirim. E-mail: thiarlax@ifes.edu.br. Orcid: https://orcid.org/0000-0002-7120-2262.

2 PhD em Educação Matemática por Indiana University. Professora aposentada pelo Instituto de Matemática da Universidade Federal do Rio de Janeiro (IM/UFRJ). Professora colaboradora voluntária no Programa de Pós-Graduação em Educação da Universidade Federal do Espírito Santo (PPGE/UFES). E-mail: profvaniasantoswagner@gmail.com. Orcid: https://orcid.org/0000-0001-9841-6191. 
de percepciones sobre las matemáticas identificadas en el dibujo de los estudiantes de lo que habían entendido de la historia. La interpretación del enunciado del problema propuesto por el maestro principiante y la respuesta de los alumnos al mismo mostró lo que los niños escucharon y entendieron sobre la tarea oral que deberían resolver mediante el dibujo. Es notorio el efecto del problema formulado por el maestro, quien, al proponerlo, pensó que solo se enfocaba en la aritmética. Por lo tanto, el texto trae algunas implicaciones de esta tarea para los lectores, ya que se cree que los maestros y estudiosos pueden investigar cuidadosamente el potencial de tareas similares cuando los estudiantes resuelven varios problemas de matemáticas.

Palabras clave: Problema de conteo. Educación Primaria, Dibujo infantil. Interpretación del enunciado del problema. Matemáticas.

\section{O COMEÇO DE UMA CONVERSA}

Vamos desenhar uma cena de acordo com o que se pede:

Há três árvores de tamanhos diferentes. Em uma árvore há 5 frutas. Em outra há 4 frutas a mais do que esta. Perto de uma árvore há uma criança. No céu voam mais pássaros que o número de árvores. Também existem flores. Mais de seis e menos de oito (Professora C, 2010).

Ao iniciar uma de suas aulas de matemática em agosto de 2010, a professora $C^{3}$ leu para suas crianças de 6 anos, matriculadas no $1^{\circ}$ ano do ensino fundamental, essa história matemática. Em seguida, solicitou que elas desenhassem a cena. Na ocasião, seu objetivo era observar o que cada um de seus alunos desenharia relacionado à ideia de quantidade. Do ponto de vista matemático, essa tarefa constituía-se em um problema para as crianças, pois, a priori, elas não possuíam um procedimento pronto para encontrar uma possível resposta (SANTOS, 1997; SANTOS-WAGNER, 2008). Por outro lado, deveriam ser estimuladas para tentar encontrar a solução, uma estratégia para resolvê-lo.

0 modo de proceder da professora $\mathrm{C}$ forneceu-nos ${ }^{4}$ pistas de que ela via a resolução de problemas como uma possibilidade metodológica para o ensino de matemática, assim como sugerem Santos-Wagner (2008), Onuchic (1999), Onuchic e Allevato (2012). Nessa perspectiva, redigiu um problema que envolveu o contexto rural em que as crianças viviam. Ao ler a tarefa, a professora $\mathrm{C}$ provocava a imaginação delas acerca do que era retratado no texto matemático. Além disso, buscava motivá-las a entender o que era lido, a fim de que a tarefa fosse resolvida.

Esse cenário incentivou-nos, em 2017, a analisar em profundidade 0 desenho de alguns estudantes do $1^{\circ}$ ano, pois, para nós, a cena desenhada constituía-se na estratégia de resolução do problema de contagem proposto pela professora C. Ao fazermos essa análise, evidenciamos a matemática subjacente ao enunciado da tarefa no que se refere à correspondência, comparação, classificação, sequenciação, seriação, inclusão e conservação, conforme descreve Lorenzato (2008). Depois, trazemos nossas percepções daquela matemática que foi possível identificar no desenho dos estudantes. Por fim, comentamos as potencialidades de tarefas como essa na prática letiva de professores.

Diante do exposto, o objetivo principal deste artigo é identificar conceitos matemáticos que as crianças evidenciaram em seus desenhos, com base no que elas haviam entendido da história lida pela professora C. Para isso, retomamos dados anteriormente não analisados na pesquisa de mestrado de Zanon (2011), quando desenvolveu uma proposta de formação continuada com as 23

3 Para fins éticos, identificamos a professora, cuja tarefa é analisada, e os alunos pelas letras iniciais de eus nomes próprios.

4 Embora o resumo tenha sido escrito na terceira pessoa do singular, redigimos o texto na primeira pessoa do plural, pois nos referimos às duas autoras deste artigo. 
professoras que ensinavam matemática em turmas de primeiro e segundo anos do ensino fundamental em escolas rurais de Castelo-ES. Ao aprofundarmos nossos estudos acerca de resolução de problemas e anos iniciais da educação básica, revimos os dados dessa formação e, de 2017 a 2019, analisamos 0 enunciado das tarefas, principalmente daquelas propostas pela professora C, como aquela mencionada no início desta seção. Também analisamos a resolução, a estratégia, e a cena desenhada por três estudantes selecionados entre os oito que compunham a turma.

As características do enunciado (POLYA, 1973) da tarefa proposta por C denota uma história matemática e orienta que a resolução seja dada por meio de desenhos. Este último representa a estratégia de resolução empregada por cada criança e indica 0 entendimento delas acerca do texto matemático $\mathrm{e}$ do conhecimento sobre outros assuntos subjacentes. Embora o problema pareça estritamente aritmético, outros conteúdos são evocados durante sua resolução. Eles podem ser identificados pelos professores na solução das crianças e assim fornecer pistas da aprendizagem delas em relação à aritmética e a outros campos matemáticos, uma vez que "ao resolver situações-problema o estudante desenvolve conceitos e habilidades, tanto na área da matemática como em diversas outras, pois estará, consequentemente, verbalizando, interpretando e produzindo novos conhecimentos" (PIMENTEL; LARA, 2015, p. 111).

Por isso, olhamos para o enunciado desse problema em especial e para os desenhos que as crianças exibiram como estratégia de resolução a partir do que entenderam da história. Assim, procuramos identificar conexões e conceitos matemáticos que essas crianças possuíam, evidenciaram e representaram em suas notações depois de terem escutado a história que a professora leu para elas. É importante salientar que vemos o desenho infantil como uma forma de expressão cultural e linguística na qual crianças manifestam sua compreensão acerca do mundo real. Por isso, sinalizam seus sentimentos e pensamentos em relação a si mesmas, ao outro e aos objetos com os quais interagem ou os quais observam ao seu redor. Na escola, os desenhos são importantes, pois representam o significado da apreensão do objeto de ensino. Em matemática, desenho é um recurso pictórico, de notação e representação que envolve "desenhos, escritas alfabéticas e algarismos" (MOR0, 2005, p. 65). Ao desenhar, a criança relaciona pensamento e ação para usar seu desenho como um recurso concreto para a comunicação entre ela e 0 outro.

Assim, entendemos que um desenho é uma manifestação do pensamento visual e uma maneira de representar o real. É também uma estratégia de registro de atividades realizadas, de resolução de problemas e de manifestação daquilo que as crianças aprenderam (DINIZ, 2001; LORENZATO, 2008; SANTOS, 1997; SANTOS-WAGNER, 2008; SMOLE, 2003). Além disso, pode ser pensado como uma forma de descrição dos progressos das notações infantis (MORO, 2005), pois, em alguns casos, a qualidade dos traços é tomada como referência para a averiguação de possíveis aprendizagens. Embora o desenho também aponte aspectos subjetivos, psicológicos e emocionais, neste estudo esses aspectos não serão focalizados. Então, fundamentadas especialmente na concepção de desenho assinalada por Diniz (2001), Lorenzato (2008), Santos (1997), Santos-Wagner (2008) e Smole (2003), buscamos alcançar o objetivo assinalado para este texto.

A seguir, trazemos os cenários metodológicos e apresentamos um panorama da pesquisa de mestrado da qual os dados se originam, da metodologia de análise empregada neste texto e dos sujeitos envolvidos (professora e alunos). Em seguida, comentamos a tarefa e interpretamos os desenhos das crianças. Ademais, procuramos identificar conceitos matemáticos que elas evidenciaram em sua resolução, a partir do que haviam compreendido ou não da história lida pela professora. Como dito anteriormente, consideramos o desenho como uma estratégia de resolução, ou seja, como uma forma de resolver a situação problemática da história. 
Nesse movimento analítico, dialogamos com a literatura, mediante a qual interpretamos o enunciado do problema e a resolução (desenho) dos alunos. Em implicações da tarefa para 0 trabalho do professor, evidenciamos potencialidades de utilização do problema por outros professores que ensinam matemática em qualquer nível escolar. Ao finalizarmos o texto, retomamos 0 objetivo principal e trazemos algumas considerações acerca dele.

\section{CENÁRIOS METODOLÓGICOS}

Trazemos aqui uma síntese da pesquisa de mestrado (ZANON, 2011) da qual os dados se originam. Na sequência, comentamos a metodologia de análise empregada neste texto, e apresentamos os sujeitos, cujos dados foram analisados. Assim, retomamos, com mais detalhes, a tarefa apresentada no início da seção anterior.

\section{A PESQUISA DE MESTRADO: ORIGEM DOS DADOS}

Desenvolvemos, em 2010, uma pesquisa qualitativa (FIORENTINI; LORENZATO, 2007; FLICK, 2009) de mestrado do tipo pesquisa-ação de caráter interventivo, por ser "uma modalidade de atuação e observação centrada na reflexão-ação" (FIORENTINI; LORENZATO, 2007, p. 112). Conduzimos oficinas de formação continuada com 23 professoras em exercício que ensinavam matemática no $1^{\circ} \mathrm{e} 2^{\circ}$ anos do ensino fundamental em escolas rurais de Castelo-ES. As oficinas ocorreram semanalmente na Secretaria Municipal de Educação (SEME). De junho a novembro de 2010, realizamos 15 encontros com duração média de três horas cada um, totalizando 120 horas de efetivo trabalho com as professoras. Os tópicos tratados foram crenças e concepções, sistema de numeração decimal, resolução de problemas, operações, avaliação, currículo e documentos oficiais, com foco nos Parâmetros Curriculares Nacionais [PCN] (BRASIL, 1997) de matemática.

Na ocasião, víamos no Brasil muitas propostas de formação continuada pensadas para ${ }^{5}$ professores. No entanto, reconhecíamos que (a) as políticas de formação continuada pouco se valiam das necessidades reais dos professores em exercício e (b) as professoras envolvidas em nossa pesquisa desejavam estudar e aprofundar conhecimentos matemáticos úteis ao exercício da docência. Esse cenário levou-nos a trabalhar diretamente $\mathrm{com}^{6}$ as professoras. Trata-se de uma formação baseada no pensamento coletivo, e não nos interesses da própria pesquisa. Desse modo, os temas das oficinas foram pensados com as professoras participantes, com base em questões relevantes para elas, em termos de ensino, aprendizagem e avaliação em matemática nos anos iniciais. Durante o processo de organização e concretização das oficinas, desenvolvemos um movimento cíclico e trabalhamos em um ir e vir constante, num diálogo em que todas fossem coparticipantes.

Essa decisão implicou nossa mudança de postura ante os processos formativos e exigiu que nossos conhecimentos matemáticos e pedagógicos de matemática (SHULMAN, 1986; 1987) estivessem mais refinados, alinhados e coerentes. Além disso, permitiu-nos ter consciência dos conhecimentos que possuíamos e daqueles que ainda precisávamos aprofundar (SANTOS, 1997). Isto foi um diferencial da formação continuada que propusemos: uma formação pensada e desenvolvida em

\footnotetext{
5 Utilizamos a expressão para ao designarmos propostas de formação continuada que são disponibilizadas pelos sistemas de ensino ou por pesquisadores sem a participação dos professores em sua elaboração.

6 A expressão com refere-se a propostas de formação continuada que são planejadas pelos formadores e/ou pesquisadores junto com os professores em processo formativo, ou seja, professores e formadores trabalham em colaboração, desde a elaboração até a execução da proposta.
} 
parceria com as professoras e implementada em um trabalho coletivo no qual o conhecimento matemático gerado foi fruto desse trabalho integrado de professores e formadores.

$\mathrm{Na}$ ocasião, todas as 23 professoras tomaram ciência dos princípios éticos que envolvem a pesquisa com seres humanos. Autorizaram 0 uso de seus dados, registros escritos, tarefas, imagens e transcrições de gravações mediante assinatura do Termo de Consentimento Livre e Esclarecido (TCLE). Os temas abordados buscavam compreender pensamentos e sentimentos das professoras sobre matemática e seu processo de ensino, aprendizagem e avaliação. Dessa forma, instrumentos e tarefas foram elaborados de forma a propiciar a tomada de consciência da relação emocional delas com a matemática (CHAPMAN, 2006; SANTOS, 1997; GÓMEZ-CHACÓN, 2003; ERNEST, 1988; THOMPSON, 1992; 1997).

0 ato de tornar-se consciente é uma forma de controle pessoal, um instrumento de mediação das relações com os outros e "um elemento chave da autorregulação da aprendizagem" (GÓMEZ-CHACÓN, 2003, p. 24). Assim, ao se tornarem conscientes dos pontos fracos e fortes de seus conhecimentos matemáticos e pedagógicos matemáticos, as professoras teriam a possibilidade de ampliar a aprendizagem delas próprias para, posteriormente, compartilhar seus conhecimentos com seus alunos (SANTOS, 1997).

Nessa perspectiva, instrumentos, tais como relatórios dos encontros redigidos no diário de campo das pesquisadoras, transcrição das gravações em áudio dos encontros, registros das professoras em seus cadernos de estudo e respostas delas às tarefas propostas nas oficinas (incluindo planejamento e desenvolvimento de aulas nas classes onde lecionavam e atividades de alunos), associaram conhecimento matemático, cognição e afeto (crenças, atitudes e emoções). Eles foram pensados a partir das leituras realizadas durante o mestrado e serviram para termos um panorama sobre quem eram as professoras em termos de comportamento em matemática (GÓMEZ-CHACÓN, 2003). Além disso, utilizamos metáforas (CHAPMAN, 2006) como uma possibilidade para acessarmos indiretamente o pensamento das professoras a respeito de seus próprios conhecimentos e das relações que elas identificavam entre eles e as práticas que desenvolviam em sala de aula. Fizemos isso pelo fato de elas terem relatado, na primeira oficina, que não gostavam de matemática, e por isso haviam cursado pedagogia.

Com o desenvolvimento da pesquisa de mestrado envolvendo professoras de diferentes perfis e experiência profissional, obtivemos muitos dados. Por isso, apenas alguns foram tratados na dissertação defendida em 2011. Olhando para os dados ainda não analisados, encontramos tarefas, tais como aquela que comentamos aqui. Assim, consideramos relevante analisar e apresentar esta tarefa aos professores e à comunidade acadêmica, visto que possuem potencial para responder a outros e novos questionamentos para além daqueles pensados anteriormente.

\section{METODOLOGIA DE ANÁLISE DAS CENAS DESENHADAS PELAS CRIANÇAS}

Ao considerarmos o viés qualitativo de pesquisa, nossas análises das cenas desenhadas pelos estudantes buscam evidenciar se (a) o problema foi resolvido, considerando o que 0 enunciado indicava; (b) a resolução se relacionava com aquela esperada pela professora; (c) os campos aritmético, algébrico e geométrico, subjacentes à tarefa, apareciam na resolução dos alunos, isto é, nos seus desenhos, e se estes campos matemáticos podem ser observados pelos professores em geral; e (d) a correspondência, comparação, classificação, sequenciação, seriação, inclusão e conservação apareciam na resolução. No Quadro 1, a seguir, apresentamos os parâmetros qualitativos 
considerados na interpretação dos dados. Nele, trazemos a matemática como a principal categoria de análise.

Quadro 1 - A matemática como categoria de análise.

\begin{tabular}{|c|c|}
\hline \multicolumn{2}{|r|}{ MATEMÁTICA } \\
\hline Parâmetros & Características consideradas \\
\hline $\begin{array}{l}\text { a) } 0 \text { aluno resolveu } 0 \\
\text { problema }\end{array}$ & $\begin{array}{l}\text { - Se o problema foi resolvido considerando o que o enunciado indicava e se a resolução tinha relação } \\
\text { com aquela esperada pela professora. }\end{array}$ \\
\hline $\begin{array}{l}\text { b) Como o aluno resolveu } \\
\text { o problema }\end{array}$ & $\begin{array}{l}\text { - Que matemática os desenhos parecem evidenciar? } \\
\text { Observaremos se os campos aritmético, algébrico e geométrico, subjacentes à tarefa, aparecem na } \\
\text { resolução, isto é, nos desenhos dos alunos. } \\
\text { - Como identificamos conceitos matemáticos nos desenhos dos alunos? } \\
\text { Noções intuitivas de aritmética: ideias de quantidade, contagem, correspondência, comparação, classifi- } \\
\text { cação, sequenciação, seriação, inclusão, conservação e sequências recursivas (a mais que, menos de); } \\
\text { Noções intuitivas de álgebra: como o conjunto de pássaros foi representado; } \\
\text { Noções intuitivas de geometria: ideias de tamanhos (grande, médio e pequeno), posicionamento e lo- } \\
\text { calização de objetos (dentro e fora, frente e trás, em cima e embaixo, entre objetos, esquerda e direita). }\end{array}$ \\
\hline
\end{tabular}

Fonte: Elaborado pelas pesquisadoras, 2019.

\section{CRITÉRIOS DE SELEÇÃO DA TAREFA E DOS ESTUDANTES}

Interessamo-nos especialmente pela tarefa proposta pela professora C aos seus alunos, pois, além de ser criativa, ela envolve, como já dito antes, os campos aritmético, algébrico e geométrico no processo de resolução. Isso possibilita que o professor trabalhe a matemática de modo integrado e perceba quais conhecimentos matemáticos seus alunos possuem. Além disso, consideramos que, ao explorarmos esta tarefa, motivaremos outros professores que ensinam matemática a formular propostas semelhantes. Em termos de pesquisa, a situação-problema mostra-se potente para respondermos a outros e novos questionamentos para além daqueles pensados anteriormente na pesquisa de mestrado.

Entre os oito estudantes que compunham a turma do $1^{\circ}$ ano, selecionamos a cena desenhada por três deles para analisarmos em profundidade. Optamos pelos desenhos de A, JP e MV em razão do entendimento deles acerca do enunciado do problema no que se refere à frase "No céu voam mais pássaros que o número de árvores". Embora a maior parte das resoluções se assemelhasse àquela do aluno A, as compreensões de JP e MV chamaram-nos a atenção, porque eles já evidenciavam um entendimento intuitivo do caráter algébrico do problema proposto (Ver detalhes na análise inserida nesse texto). Com o propósito de melhor apresentá-los, trazemos, na sequência, um panorama da professora $\mathrm{C}$ e dos alunos A, JP e MV. 


\section{OS SUJEITOS}

\section{A PROFESSORA C}

Em 2010, quando as oficinas de formação continuada (ZANON, 2011) foram desenvolvidas, a professora C lecionava, na condição de professora de designaç̧ão temporária (DT), no $1^{\circ}$ ano do ensino fundamental havia quatro meses. Tinha acabado de concluir o curso de pedagogia. Nas oficinas, seu comportamento era espontâneo e não apresentava receio em compartilhar dúvidas sobre seu conhecimento e sobre o processo de ensino, aprendizagem e avaliação que desenvolvia. Huberman (1993) ajuda-nos a compreender melhor o comportamento dessa professora, quando identifica e delimita sete fases perceptíveis da carreira docente: (1) entrada na carreira; (2) estabilização; (3) experimentação e diversificação; (4) pôr-se em questão; (5) serenidade e distanciamento afetivo; (6) conservadorismo e lamentações; e (7) desinvestimento.

Nessa lógica, a professora $\mathrm{C}$ estava em seus primeiros meses de docência como regente de uma turma. Essa seria a primeira etapa no ciclo do magistério descrita por Huberman (1993). Ela é marcada pela sobrevivência e pela descoberta. Esses aspectos caminham paralelamente. No entanto, é a descoberta que possibilita ao professor em início de carreira sobreviver aos desafios da profissão docente. A sobrevivência "traduz o que se chama vulgarmente o 'choque do real', a confrontação inicial com a complexidade da situação profissional" (HUBERMAN, 1993, p. 39). A descoberta "traduz o entusiasmo inicial, a experimentação, a exaltação por estar, finalmente, em situação de responsabilidade (ter a sua sala de aula, os seus alunos, o seu programa)" (HUBERMAN, 1993, p. 39).

Tanto a professora $\mathrm{C}$ como as demais 22 professoras, em início de carreira e/ou em diferentes fases da docência, participaram das oficinas de formação continuada. Assim, foi necessário tecermos um panorama sobre quem eram essas professoras em termos de comportamento em matemática. Para isso, valemo-nos de metáforas (CHAPMAN, 2006) para acessar o pensamento delas. Então, apresentamos, na primeira e na última oficina, a seguinte frase para cada participante completar e também explicar seus argumentos: "Para mim a matemática é como... Por quê?". As participantes deveriam responder em poucos minutos, com as primeiras imagens que thes viessem à mente. Trazemos, no Quadro 2, as imagens usadas pela professora $\mathrm{C}$, para expressar 0 que era a matemática para ela no início e no fim das oficinas desenvolvidas em 2010.

Quadro 2 - Desenhos da professora C para responder "Para mim a matemática é como... Por quê?"

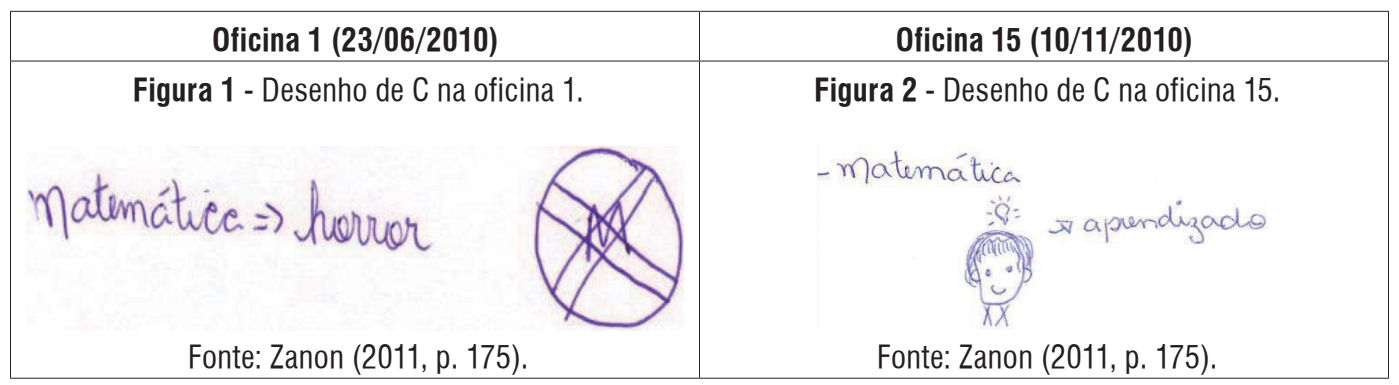

Fonte: Dados da pesquisa de mestrado (ZANON, 2011, p. 175).

7 Embora C não seja uma das autoras deste texto, a tarefa aqui analisada foi elaborada por ela. Por isso, consideramos importante trazer um panorama dessa professora. 
Na oficina inicial e na final, nós também solicitamos que as 23 professoras participantes das oficinas escrevessem livremente sobre a matemática. Para isso, iniciamos um diálogo com base neste fragmento: "0 que eu gostaria de dizer sobre a matemática é...". A professora C registrou:

Algo sem prazer, que eu tenho que saber por saber, sem lógica alguma. Que eu gostaria de entender os "porquês" e os "para quê", para que o meu aprendizado se tornasse prazeroso. Como uma coisa muito interessante e prazerosa, tentaria explicar como ela acontece na nossa vida (Professora C, 6 de junho de 2010).

Quando observamos somente a imagem usada por $\mathrm{C}$ na oficina 1 e esse fragmento, temos pistas de que essa professora chegou às oficinas apresentando indícios de crenças negativas sobre a aprendizagem de matemática e com alguns desejos de entender esse conhecimento, conteúdo ou disciplina. Segundo Gómez-Chacón (2003), esse tipo de crença é construído pelo sujeito quando, na condição de aluno, é exposto a alguma situação de aprendizagem que não corresponde às suas expectativas. Assim, ele, 0 aluno, sente grande insatisfação, o que interfere em sua motivação para aprender matemática. Se olharmos apenas o fragmento acima, notamos indícios de crenças negativas sobre matemática: "Algo sem prazer", "tenho que saber por saber", "sem lógica". Isso reforça seu sentimento negativo em relação à matemática como disciplina. Essa crença representa as próprias certezas que uma pessoa tem sobre a matemática e afeta a maneira como acredita que a disciplina deve ser ensinada (GÓMEZ-CHACÓN, 2003). Tal fato é confirmado quando a professora C registra "tentaria explicar como ela acontece na nossa vida", reforçando a ideia de como a matemática deveria ser ensinada.

Conforme podemos observar, essa crença mencionada por Gómez Chacón (2003) influencia na forma como o professor pensa sobre a matemática (ERNEST, 1988) e o seu ensino (THOMPSON, 1997). Caso tal crença não se torne consciente (SANTOS, 1997), pode ocasionar um ciclo vicioso no qual professores que ensinam matemática e não gostam de matemática acabam ensinando seus alunos a não gostar também desse conhecimento. Caso esses alunos venham, futuramente, a se tornar professores, tenderão a reproduzir o mesmo pensamento.

Isso pode ser explicado por Thompson (1997), quando estudou o comportamento de professores em sala de aula. Discute crenças e concepções deles e sua relação com a prática que desenvolvem. Para a autora, a análise desses processos evidencia como concepções sobre a matemática influenciam na formação das caraterísticas da prática pedagógica desses professores. Afirma que "os professores desenvolvem padrões de comportamento característicos de sua prática pedagógica" (THOMPSON, 1997, p. 12) que podem ser sustentados consciente ou inconscientemente.

Ernest (1988) já apontava que o professor pode entender a matemática segundo três modelos de crenças e concepções que implicam os comportamentos e práticas docentes. 0 texto clássico de Thompson (1992), com uma síntese de pesquisa sobre crenças e concepções, e um artigo sobre sua pesquisa de doutorado (THOMPSON, 1997) expõem padrões de comportamentos dos professores a respeito da natureza da matemática. Assim, concordamos com esses autores quando dizem que a matemática pode ser entendida sob três visões distintas: como um instrumento, como corpo estático e unificado do conhecimento e como um campo de criação humana em grande e constante expansão.

Em linhas gerais, com base na análise desses e de outros instrumentos e tarefas, a professora C apontou indícios de possuir uma visão de matemática que transitava entre a utilitária e a platônica. Segundo a visão utilitária, a matemática é vista como um instrumento útil para atingir um fim. É entendida 
como um conjunto de fatos, regras e procedimentos independentes, porém utilitários. Já conforme a visão platônica, a matemática é entendida como um corpo estático e unificado de conhecimentos, no qual os conteúdos matemáticos são considerados como prontos e acabados.

Diante disso, nós, pesquisadoras, dialogamos com todas as 23 professoras participantes das oficinas para desafiá-las a pensar, refletir e tomar consciência de seus conhecimentos e sentimentos sobre matemática. Esse diálogo com elas foi importante, porque, com exceção de uma professora, que possuía licenciatura plena em Matemática, as demais 22 docentes demonstraram sentimentos negativos em relação à matemática e ao seu processo de ensino, aprendizagem e avaliação. Fizemos assim por acreditar que, se as professoras desenvolvessem e demonstrassem sentimentos mais positivos em relação à matemática, o desejo de aprendê-la e ensiná-la sem medos e anseios poderia ser despertado. Nosso desejo era evitar, nas oficinas, que matemática e aprendizagem de conhecimentos matemáticos fossem consideradas como monstros pelas professoras, porque sabemos que podemos criar monstros que nos paralisam, pelo fato de não sabermos de que maneira eles funcionam e devemos lidar com eles (LINS, 2012).

Quando olhamos novamente para os dados apresentados por C, observamos que, na oficina 15, em 10/11/2010, ela saiu de uma atitude negativa em relação à matemática (conforme exibia na oficina 1) para uma atitude positiva, de desejo e possibilidade de aprender. Esse comportamento mostrou que a professora alterou muito seu modo de pensar e sentir a matemática em sua atividade docente, o que the permitiu desenvolver um novo olhar sobre a matemática (ERNEST, 1988; SANTOS, 1997; THOMPSON, 1992; 1997), que deixou de ser algo com o qual ela não sabia lidar.

Quase oito anos após a realização das oficinas de formação continuada, contatamos novamente a professora C para sabermos detalhes profissionais dela e da tarefa que apresentou em 2010, durante as oficinas. Atualmente ela é professora efetiva de uma escola municipal de ensino fundamental de Marataízes-ES. Em 2018, quando dialogamos com ela, já atuava havia três anos como professora da educação especial. Ela acompanhava, em todas as disciplinas, alunos do $1^{\circ}$ ao $5^{\circ}$ ano matriculados em classes regulares de ensino. Explicou-nos que o número de alunos acompanhados varia em função do tipo de necessidade que cada um apresenta, pois é resguardada a individualidade de cada aluno.

Seu trabalho consiste em traduzir as aulas regulares, no momento em que elas acontecem, aos alunos com os quais trabalha, possibilitando que eles compreendam, na medida do possível, o conteúdo que está sendo ensinado. Informou-nos que hoje trabalha a matemática com mais segurança e a vê como possível de ser ensinada por ela e aprendida por seus alunos. Destacou que as oficinas, das quais participou em 2010, permitiram que ela pensasse mais no que ainda precisava aprender em matemática (SANTOS, 1997) e a ajudaram a ter uma atitude proativa em relação a essa disciplina. Huberman (1993) permite-nos ver que, nesse momento, com oito anos de docência, a professora C se encontra na fase de estabilização. No ensino, no que diz respeito à estabilização, "[...] trata-se, a um tempo, de uma escolha subjetiva (comprometer-se definitivamente) e de um ato administrativo (a nomeação oficial)" (HUBERMAN, 1993, p. 40). Isso pode representar a independência, o pertencimento a um corpo de profissionais e um sentimento crescente de competência pedagógica.

\section{OS ALUNOS A, JP E MV}

A, JP e MV eram crianças com 6 anos de idade em 2010. Cursavam $01^{0}$ ano do ensino fundamental. Eles já conseguiam ler algumas palavras e formar frases pequenas, relacionavam quantidades e desenvolviam as tarefas propostas pela professora C. Segundo ela 0 aluno A era muito 
comunicativo e conversava bastante durante as aulas. Era uma criança que precisava estar envolvida em inúmeras tarefas o tempo todo. 0 aluno JP era introspectivo, sempre muito quieto e concentrado. Percebia todos os acontecimentos da sala de aula. Gostava muito de desenhar. Já MV era uma criança que se apresentava muito dispersa em sala de aula. Estava sempre ocupada com os próprios pensamentos. A professora C relatou-nos que, quando se aproximava dela em sala de aula, MV gostava de relatar os acontecimentos de sua casa. Era uma criança que conseguia desenvolver todas as tarefas. No entanto, mostrava-se muito desanimada quando tinha que desenhar alguma coisa.

\section{A TAREFA ELABORADA E DESENVOLVIDA PELA PROFESSORA C}

Vamos desenhar uma cena de acordo com 0 que se pede:

Há três árvores de tamanhos diferentes. Em uma árvore há 5 frutas. Em outra há 4 frutas a mais do que esta. Perto de uma árvore há uma criança. No céu voam mais pássaros que o número de árvores. Também existem flores. Mais de seis e menos de oito (Professora C, 2010).

A tarefa acima proposta pela professora $\mathrm{C}$ aos seus alunos do $1^{\circ}$ ano do ensino fundamental, incluindo $\mathrm{A}$, JP e MV, foi concebida por ela após a oficina 6 , na qual a resolução de problemas foi 0 tema abordado. Devido à intensidade e curiosidade das 23 participantes, 0 tema estendeu-se às oficinas 7 e 8. Na ocasião, nós, pesquisadoras, em colaboração com as professoras, tínhamos interesse em saber como as participantes das oficinas compreendiam e abordavam a resolução de problemas nas escolas da zona rural de Castelo-ES. Um dos tópicos assinalados por nós, pesquisadoras, foram as perspectivas distintas de ensinar matemática com foco na resolução de problemas. À época, respaldamo-nos nos estudos de Schroeder e Lester (1989), que as distinguem da seguinte maneira: a) ensinar sobre a resolução de problemas; b) ensinar para a resolução de problemas; e c) ensinar via/ através/por meio da resolução de problemas.

Os autores mencionados, assim como seus contemporâneos (SANTOS-WAGNER, 2008; ONUCHIC, 1999; ONUCHIC, ALLEVATO, 2012), destacam que as três formas são necessárias e ensinar matemática via resolução de problemas é uma maneira de relacionar conceitos matemáticos e fazer matemática. Entretanto, consideramos que nem sempre os professores sabem, mediante a resolução de um problema, como podem formalizar conceitos matemáticos. 0 ideal seria ter professores que incorporassem essas três formas de ensinar matemática em suas aulas, pois todas são importantes e necessárias. Ademais, os professores deveriam desejar aprender a selecionar e/ou formular problemas que servissem como disparadores para que conceitos matemáticos fossem ensinados por meio da resolução desses problemas, mas sabemos que essa forma de ensinar é bem mais complexa (ZANON, 2019).

Diante de um enunciado de um problema matemático, Polya (1973) sugere que seja feita uma série de questionamentos acerca dele, porque isso pode a) auxiliar 0 aluno a resolver 0 problema apresentado, mediante as indagações do professor, e b) desenvolver a capacidade de pensar sobre as próprias questões a fazer a si próprio e resolver problemas sozinho. Segundo Polya (1973), as questões que sugere para cada fase da resolução de problemas

[...] são igualmente úteis àquele que procura resolver problemas por si próprio. Se o leitor ficar suficientemente familiarizado com esta lista e conseguir perceber, por detrás da sugestão, a ação sugerida, ele verá que a lista enumera, indiretamente, 
operações mentais mais típicas, úteis para a resolução de problemas (POLYA, 1973, p. 2, grifo do autor).

Notamos que, diante de um enunciado proposto, Polya (1973) evidencia a necessidade de um diálogo entre professor e alunos, tendo por objetivo compreender o problema. Por isso, 0 enunciado da tarefa em questão foi redigido em letras maiúsculas, no centro superior de uma folha de papel tamanho ofício. A professora $\mathrm{C}$ entregou a atividade a cada aluno, que deveria resolver a situação desenhando, na parte inferior da folha, a cena indicada no problema. Para isso, a professora $\mathrm{C}$ esperou que os alunos estabelecessem um primeiro contato visual com a tarefa. Como metodologia de ensino, explicou que faria a leitura de cada frase do enunciado pausadamente e aguardaria a resolução (0 desenho) de todos os alunos, para prosseguir com a leitura da tarefa.

Segundo a professora C, o problema foi pensado principalmente pelo fato de tratar da contagem e da sequência numérica de 1 a 9 . É sabido que, nos anos iniciais do ensino fundamental, 0 sistema de numeração decimal, a contagem e a sequência numérica devem ser problematizados e tratados em diferentes tarefas, para que as crianças se sintam instigadas a aprender esse conteúdo. Assim, a ideia de trabalhar com essa tarefa partiu da descrição desses conteúdos no currículo e foi elaborada pela própria professora $\mathrm{C}$ mediante conversas com outros professores mais experientes.

A professora $\mathrm{C}$ relatou que, durante 0 estágio supervisionado, ao observar 0 comportamento de professores em diferentes momentos (sala de aula, recreio, sala de professores, planejamentos), notou que eles conversavam sobre tarefas e elaboravam aquelas que envolviam a ideia de contagem, de desenhar quantidades. Nessas tarefas, eles solicitavam que alunos desenhassem quantidades de árvores, crianças, bonecas, carrinhos entre outros. Depois, quando começou a lecionar, incorporou algumas dessas ideias em sua prática. Ouviu também professores comentando essas mesmas ideias nas oficinas de formação continuada em 2010. Por isso, quando lhe solicitamos que trouxesse um exemplo de atividade, ela mesma elaborou essa tarefa que envolvia a ideia de contagem, realizou-a com os alunos e compartilhou-a conosco.

Para a professora $\mathrm{C}$, a tarefa tinha 0 objetivo de permitir que os alunos (a) relacionassem números a quantidades e (b) descrevessem tamanhos e proporções diferentes. Para isso, considerou ter desenvolvido uma aula expositiva, tradicional de resolução de problemas. Essa tarefa foi aplicada em agosto/2010, e alguns alunos, dos oito que compunham a turma na qual lecionava, ainda estavam em processo de aprendizagem de leitura e escrita. Embora os alunos A, JP e MV já conseguissem ler algumas palavras e formar pequenas frases, os demais cinco estudantes ainda não estavam no mesmo nível de apropriação da leitura e da escrita, por isso não houve interação reflexiva entre a professora C e a turma. Ela esperava que os alunos desenhassem: (a) três árvores, sendo uma grande, uma média e uma pequena; (b) cinco frutas em uma árvore e nove frutas em outra; (c) uma criança (poderia ser ela mesma, a própria criança, ou outra); (d) quatro pássaros; (e) sete flores. Em 2018, quando conversamos com a professora $\mathrm{C}$ acerca dessa tarefa, ela nos informou que ainda hoje trabalha com tarefas que envolvem ideias semelhantes, tendo em vista a compreensão do conceito de número pelos alunos.

\section{QUANDO NÚMEROS SÃO REPRESENTADOS EM DESENHOS: INTERPRETANDO AS ESTRATÉGIAS DAS CRIANÇAS}

Os desenhos das crianças foram analisados e interpretados posteriormente à pesquisa de mestrado (ZANON, 2011), à luz dos estudos dos autores mencionados no corpo do texto. Aqui trazemos 
uma síntese de nossa compreensão acerca das resoluções por meio de desenhos de A, JP e MV e, a partir delas, dialogamos com a literatura estudada. As resoluções apresentadas denotam uma construção de sentido e pensamento matemático mediante as representações simbólicas, os desenhos produzidos. Embora, à primeira vista, a tarefa pareça simples, ela tem um vasto potencial matemático, por isso a consideramos bem criativa.

Desse modo, nossa análise incidirá sobre a identificação dos conceitos matemáticos que as crianças evidenciaram em seus desenhos com base, no que elas haviam entendido da história lida pela professora $\mathrm{C}$. Evidenciaremos as noções de aritmética quando os alunos apontarem as ideias de quantidade, contagem, correspondência, comparação, classificação, sequenciação, seriação, inclusão, conservação e sequências recursivas (a mais que, menos de). Ao observarmos como as crianças compreendem a frase "No céu voam mais pássaros que a quantidade de árvores", teremos algum indício do entendimento delas acerca de uma quantidade genérica. Isso pode ser visto quando alunos desenham uma quantidade qualquer de pássaros, uma vez que na história há a informação de que voam mais pássaros no céu do que o número de árvores.

Vê-se que não há uma delimitação da quantidade exata de elementos do conjunto de pássaros. Neste ponto, como a ideia de conjunto também aparece subjacente à tarefa sinalizando uma possível relação entre ideias aritméticas e algébricas, olharemos qual a noção de conjunto apresentada pelos alunos e de que forma ela aparece na resolução dada por eles. Em relação ao campo geométrico, analisaremos as noções de medidas relacionadas aos diversos tamanhos e também noções espaciais elementares, envolvendo posicionamento e localização de objetos (dentro e fora, frente e trás, em cima e embaixo, entre objetos, esquerda e direita).

0 problema foi elaborado, em 2010, pela professora C, tendo, na sequência numérica e na contagem, seus principais focos. Na ocasião, tinha por referência as orientações curriculares municipais construídas com base no Currículo Básico Comum das Escolas da Rede Estadual de Ensino [CBC] (ESPÍRITO SANTO, 2009), disponibilizado pela Secretaria da Educação do Espírito Santo (SEDU-ES). Isso porque as diretrizes curriculares adotadas nas escolas de Castelo-ES são regulamentadas em sentido mais amplo pelas orientações federais e estaduais.

Se olharmos o problema desenvolvido pela professora $\mathrm{C}$ a partir da Base Nacional Curricular Comum [BNCC] (BRASIL, 2017), verificaremos a atualidade dele. Na BNCC (BRASIL, 2017) vê-se que a matemática é organizada em unidades temáticas (números, álgebra, geometria, grandezas e medidas e probabilidade e estatística) e objetos de conhecimentos associados a elas. Assim, a tarefa elaborada pela professora C em 2010 é uma tarefa que atende ao proposto pelo novo documento oficial norteador das atividades de ensino, quando consideramos, por exemplo, que 0 problema permite ao aluno a aprendizagem de números, álgebra e geometria. Vale ressaltar, que os documentos CBC (ESPÍRITO SANTO, 2009) e PCN (BRASIL, 1997) já reforçavam esses argumentos que a BNCC (BRASIL, 2017) agora destaca. Além disso, os documentos anteriores e este mais recente sinalizam que conhecimentos matemáticos podem ser produzidos com base na resolução de problemas, pois possibilitam a integração entre os campos matemáticos e atende aos conteúdos prescritos para a faixa etária.

Embora nem tudo isso estivesse claro para a professora $\mathrm{C}$, que o formulou e aplicou com seus alunos em 2010, nós, pesquisadoras, pensamos ser relevante mencionarmos essas ideias neste texto. Diante desse cenário, questionamos: será que professores que ensinam matemática nos anos iniciais identificam todo esse potencial nessa tarefa? Será que professores conseguem identificar 0 8 Grifo nosso. 
potencial matemático das tarefas que planejam e sabem dialogar e provocar seus alunos para que aprendam matemática?

Na sequência, trazemos, no Quadro 3, nossa interpretação das resoluções dos alunos A, JP e MV com base nos parâmetros por nós definidos e apresentados anteriormente no Quadro 1. As cenas desenhadas pelos três estudantes foram as seguintes:

Quadro 3 - Resolução dos alunos A, JP e MV.

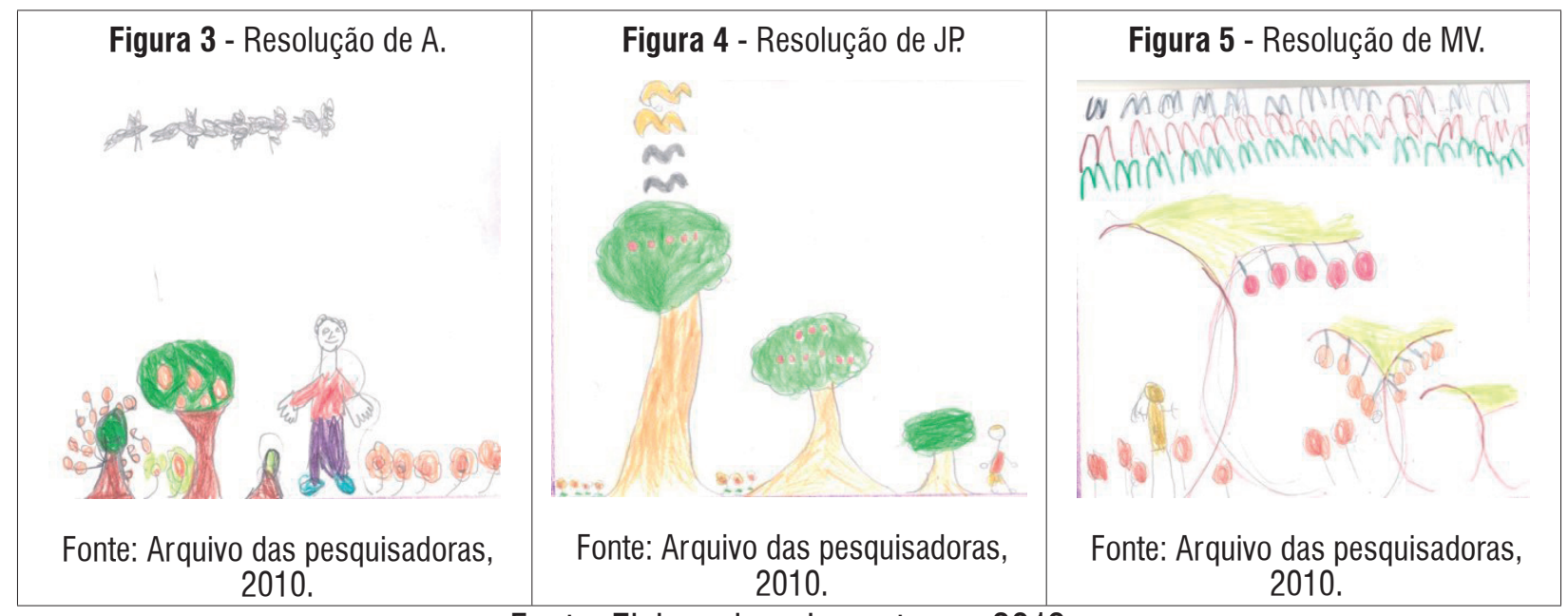

Fonte: Elaborado pelas autoras, 2019.

Ao tomarmos por referência o parâmetro o aluno resolveu o problema, salientamos que, no geral, os desenhos, em sua maioria, correspondiam ao que se pedia no enunciado e ao que a professora C esperava como resposta. No entanto, os alunos A e MV desenharam pássaros a mais do que a quantidade esperada pela professora. Note-se que os desenhos representam o repertório imagético das crianças quanto à qualidade e aproximação das imagens aos objetos reais como aparecem no ambiente natural.

No parâmetro como o aluno resolveu o problema, vê-se que os campos aritmético, algébrico e geométrico aparecem nas resoluções das crianças. Então, o que conseguimos identificar de conhecimentos matemáticos nas cenas desenhadas pelos estudantes? Acreditamos que 0 aluno deveria compreender a noção de correspondência, comparação, classificação, sequenciação, seriação, inclusão e conservação e saber operar com alguns deles. Lorenzato (2008, p. 25) informa que, "se o professor não trabalhar com as crianças esses processos, elas terão grandes dificuldades para aprender número e contagem, entre outras noções".

Isso mostra que, embora a literatura mencione que esses processos devam ser focalizados na educação infantil, no $1^{\circ}$ ano do ensino fundamental, a criança pode não os ter desenvolvido adequadamente. Por isso, o professor deve ser sensível e cuidadoso, ao elaborar atividades como 0 problema proposto pela professora C, cujas ideias estão subjacentes à resolução das crianças. Então, podemos indagar: como esses processos podem aparecer nos desenhos (resoluções) de alunos e ser observados por outros professores? Detalhando, teríamos: 
Quadro 4 - Processos, características e como eles podem aparecer na resolução da tarefa.

\begin{tabular}{|c|c|c|}
\hline PROCESSOS & $\begin{array}{c}\text { CARACTERÍSTICAS } \\
\text { (LORENZATO, 2008, p. } 25 \text { - 27) }\end{array}$ & $\begin{array}{l}\text { COMO ELES APARECERAM NA } \\
\text { RESOLUÇÃO DA TAREFA }\end{array}$ \\
\hline Correspondência & $\begin{array}{l}\text { "[...] é } 0 \text { ato de corresponder um a } \\
\text { um” (p. } 25) .\end{array}$ & $\begin{array}{l}\text { Quando o aluno associa uma quantidade ao número anunciado pela professora } \\
\text { e desenha os objetos mencionados representando a quantidade indicada. }\end{array}$ \\
\hline Comparação & $\begin{array}{l}\text { “[...] é o ato de estabelecer diferen- } \\
\text { ças ou semelhanças" (p. 26). }\end{array}$ & $\begin{array}{l}\text { Quando a criança compara o tamanho das árvores, pois elas não deveriam ser } \\
\text { do mesmo tamanho, e a quantidade de cada objeto a ser desenhado. }\end{array}$ \\
\hline Classificação & $\begin{array}{l}\text { “[...] é o ato de separar em catego- } \\
\text { rias de acordo com semelhanças } \\
\text { e diferenças" (p. 26). }\end{array}$ & $\begin{array}{l}\text { Árvores e flores possuem raízes. Precisam estar afixadas ao solo. Frutas } \\
\text { estariam nos galhos das árvores e pássaros voam no céu. } 0 \text { aluno parece } \\
\text { ter essa compreensão dessas suposições à medida que demonstra, por seus } \\
\text { desenhos, que pássaros, por exemplo, têm características que os diferem das } \\
\text { árvores, flores, criança. }\end{array}$ \\
\hline Sequenciação & $\begin{array}{l}\text { "[...] é } 0 \text { ato de fazer suceder a cada } \\
\text { elemento um outro sem considerar } \\
\text { a ordem entre eles" (p. 26). }\end{array}$ & $\begin{array}{l}\text { Para construírem a cena, os alunos executaram ações uma a uma. Observe a } \\
\text { organização dos elementos nos desenhos. Por exemplo, não importa a ordem } \\
\text { em que as árvores foram desenhadas, mas, sim, que três árvores, de tama- } \\
\text { nhos distintos, tenham sido desenhadas independentemente da ordem em que } \\
\text { aparecem. Isso se aplica também aos pássaros, flores e frutas. }\end{array}$ \\
\hline Seriação & $\begin{array}{l}\text { “[...] é } 0 \text { ato de ordenar uma sequ- } \\
\text { ência segundo um critério" (р. 26). }\end{array}$ & $\begin{array}{l}0 \text { enunciado do problema propunha uma orientação a partir da qual os objetos } \\
\text { deveriam ser desenhados. Isso implica a inclusão do vocabulário específico } \\
\text { (primeiro, segundo, terceiro...) no qual a ordinalidade é evocada: primeiro, } \\
\text { árvores; depois, frutas, criança, pássaros e flores. }\end{array}$ \\
\hline Inclusão & $\begin{array}{l}\text { “[...] é o ato de fazer abranger um } \\
\text { conjunto por outro" (p. 27). }\end{array}$ & $\begin{array}{l}\text { Ao resolver o problema, o aluno deveria desenhar, por exemplo, } 7 \text { flores. Para } \\
\text { completar esta quantidade, ele deveria incluir os outros números }(1,2,3,4,5 \text {, } \\
6 \text { ) até compor o conjunto de } 7 \text { elementos. Isso implica saber que, dentro de } \\
\text { uma quantidade, existem outras. }\end{array}$ \\
\hline Conservação & $\begin{array}{l}\text { “.... é o ato de perceber que a } \\
\text { quantidade não depende da arru- } \\
\text { mação, forma ou posição” (p. 27). }\end{array}$ & $\begin{array}{l}\text { Isto pode ser percebido nos desenhos de árvores, frutas e flores. Note que fica } \\
\text { mais evidente quando os alunos desenharam as flores. A desenhou } 2+5 \text {, JP } \\
\text { desenhou } 4+3 \text { e MV desenhou } 3+2+2 \text {. Observe ainda a disposição das } \\
\text { frutas nas árvores: independentemente da forma como foram arrumadas, a } \\
\text { quantidade permanece. }\end{array}$ \\
\hline
\end{tabular}

Fonte: Elaborado pelas pesquisadoras, 2019.

Como dito anteriormente, a professora $\mathrm{C}$ considerou que o problema elaborado por ela era essencialmente de contagem. Assim, não relacionou a aprendizagem da contagem com a correspondência, comparação, classificação, sequenciação, seriação, inclusão e conservação. Embora no problema estivesse mais evidente a correspondência um a um, queremos dizer que outras ideias matemáticas estavam subjacentes a ele. Por isso, acreditamos que um professor atento, ao perceber a correspondência, comparação, classificação, sequenciação, seriação, inclusão e conservação, nessa atividade, poderá verificar se, de fato, 0 aluno entendeu 0 conceito de número e a ideia de contagem inerente a ele.

Lorenzato (2008, p. 27) afirma que essas ideias "são abrangentes e constituem-se num alicerce que será utilizado para sempre pelo raciocínio humano, independentemente do assunto ou tipo de problema a ser enfrentado". 0 autor também chama a atenção para o fato de que a apreensão dessas noções pela criança implica a construção do conceito de número. Trata-se de um processo que não é linear e no qual as atividades que envolvem a noção de quantidade têm papel fundamental.

0 professor que tem habilitação em licenciatura/bacharelado em Matemática e leciona para além do $1^{\circ}$ ano do ensino fundamental pode observar, nos desenhos dos alunos, algumas noções intuitivas de álgebra. Isso aparece na representação da sentença "No céu voam mais pássaros que 
a quantidade de árvores" ". Vê-se que a quantidade de pássaros se apresenta indefinida, não delimitada, se mostra genérica e infinita e indica uma quantidade desconhecida. Assim, poderia ser pensada e representada, por exemplo, pela letra $n$ para representar uma quantidade qualquer $n$ de pássaros. Ou seja, mediante a interpretação da sentença, os alunos poderiam desenhar uma quantidade qualquer $n$ de pássaros que fosse igual ou superior a quatro, embora a professora esperasse quatro como resposta.

Ao observarmos os desenhos dos alunos A, JP e MV, notam-se cinco, quatro e 41 pássaros, respectivamente. Vê-se que JP representou o esperado pela professora. Já A e MV apresentaram resoluções diferentes que nos permitem refletir acerca de alguns pontos: que interpretações os enunciados de problemas permitem? Que respostas são esperadas? Quais respostas são possíveis? Como o professor vai interpretar as respostas e, neste caso, como a ideia de conjunto (finito/infinito) aparece subjacente à tarefa, cristalizando uma relação entre aritmética e álgebra? No último caso, MV mostrou que a interpretação dele sobre a quantidade de pássaros poderia ser infinita, pois poderia desenhar qualquer quantidade inteira. A análise dessa situação permite-nos aferir que a estrutura das frases que compõem um problema verbal interfere na forma como as resoluções são apresentadas (POLYA, 1973). Além disso, o professor deve dialogar com os alunos para compreender o pensamento deles acerca dessas noções e para permitir que outros alunos entendam como seus colegas pensam e interpretam situações como essa, pois as crianças "[...] são capazes de criar diferentes estratégias de resolução e comunicar-se utilizando a oralidade, a representação pictórica e a escrita" (PIMENTEL; LARA, 2015, p. 109).

Os desenhos dos alunos A, JP e MV também nos informam sobre 0 entendimento deles acerca do campo geométrico. Vemos indícios de noções de medidas relacionadas aos diversos tamanhos e também noções espaciais elementares, envolvendo posicionamento e localização de objetos (dentro e fora, frente e trás, em cima e embaixo, entre objetos, esquerda e direita). Lorenzato (2008) argumenta que a percepção espacial é fundamental no desenvolvimento infantil, pois a criança de 6 ou 7 anos utiliza-se dela para aprender a ler, escrever, desenhar, jogar, entre outras atividades. Afirma também que o grande objetivo do ensino da geometria "é fazer com que a criança passe do espaço vivenciado para o espaço pensado" (LORENZATO, 2008, p. 45). Portanto, o ensino da geometria deve, então, acontecer da dimensão topológica para a euclidiana, passando, assim, do plano concreto ao abstrato.

Corroborando essa ideia, Smole (2003) menciona que, quando a criança chega à escola, traz consigo inúmeras noções de espaço construídas mediante suas interações com o contexto social e progressivamente cria "formas de representação desse mundo: imagens, desenhos, linguagem verbal” (SMOLE, 2003, p. 105). Assim, as noções geométricas seguem três etapas: vivida, percebida e concebida, 0 que, nas palavras de Lorenzato (2008), equivale às dimensões topológica, projetiva e euclidiana, que são de inspiração piagetiana.

Ainda observando os desenhos de A, JP e MV, percebemos que eles rememoram, lembram e transpõem para o papel imagens de árvores, flores, criança, frutas e pássaros, independentemente de esses elementos estarem sob seu campo visual. Traduzem em imagem uma recordação. Essa habilidade para a percepção espacial é denominada memória visual. Refere-se "à habilidade de lembrar-se daquilo que não está mais sob sua vista" (LORENZAT0, 2008, p. 47). Nos desenhos, a memória visual das crianças é percebida quando: (1) desenham árvores de tamanhos distintos (grande, médio e pequeno); (2) posicionam e localizam, por exemplo, frutas dentro e fora das árvores, pássaros em cima das árvores, flores e criança, e desenham árvores e flores afixadas no solo, apresentando a ideia de embaixo; e (3) utilizam cores próximas àquelas em que os objetos se apresentam na natureza. 
Mesmo que tais noções não tenham sido exigidas, o cenário é composto com base na memória visual das crianças. Vemos, ainda, que os alunos resolveram o problema "criando estratégias próprias para sua resolução, desenvolvendo a imaginação e a criatividade” (ESPÍRITO SANTO, 2009, p. 81).

Lorenzato (2008) enfatiza que o tripé básico dos conhecimentos matemáticos recomendados para os anos iniciais do ensino fundamental se constitui pelos sensos de medida, geométrico e numérico. Isso também é evidenciado em documentos oficiais que norteiam atividades de ensino na escola básica. Nesse cenário, a escola

[...] deve auxiliar as crianças a ter um contato mais sistemático com essas mesmas noções, proporcionando-Ihes a elaboração de significados matemáticos. Torna-se necessário planejar o trabalho de sala de aula, objetivando orientar as ações da criança por meio de situações-problema, de modo que ela possa desenvolver com significados próprios as operações lógicas envolvidas nas noções matemáticas abordadas no problema (LORENZATO, 2008, p. 57).

Assim, na sequência, trazemos algumas ideias que podem auxiliar professores a ampliar o problema dado, a fim de que explorem os conteúdos acima mencionados e outros tópicos matemáticos. 0 intuito seria mais 0 de problematizar e verificar o que estudantes compreendem, pensam, sabem e demonstram no tocante ao conhecimento matemático, com vistas a sinalizar quais atividades 0 professor deverá propor.

\section{IMPLICAÇÕES DA TAREFA PARA O TRABALHO DO PROFESSOR}

0 problema cuja resolução foi discutida neste texto tem muito potencial matemático. Mas esse potencial só será percebido à medida que o professor amplie seu conhecimento matemático e pedagógico de matemática (SHULMAN, 1986; 1987), e reflita acerca dos conhecimentos que tem e dos que ainda precisa aprofundar, melhorar e aprender (SANTOS, 1997). Além disso, o professor precisa saber como seus alunos aprendem matemática, como compreendem os enunciados dos problemas e como operam com as informações neles contidas, pois é o professor que dará forma à matemática que ensina às crianças. As suas crenças, concepções e visões de matemática (ERNEST, 1988; THOMPSON, 1997, GÓMEZ-CHACÓN, 2003) e do seu processo de ensino, aprendizagem e avaliação terão um impacto significativo na maneira como os alunos aprendem e lidam com a matemática. Ademais, sugerimos que os professores reconheçam e compreendam o que sabem e ainda não sabem (SANTOS, 1997) acerca desses conhecimentos, tanto no plano propriamente matemático quanto no pedagógico, e da forma pela qual usam esses conhecimentos em seus processos de ensino e de avaliação.

Quando pensamos no planejamento de uma aula baseada em resolução de problemas, usamos as ideias de Van de Walle (2009). Ele menciona nove passos para o planejamento de uma atividade desse tipo, entre os quais o autor informa que os quatro primeiros são os mais importantes, por definirem a essência da aula. Assinala que o primeiro passo é começar pela matemática. 0 professor deve pensar na matemática a ser ensinada/aprendida em níveis conceituais. 0 segundo se refere aos alunos. 0 professor deve, por exemplo, questionar-se: quem são meus alunos em termos de conhecimento matemático? Que experiência eles já tiveram ou não com ele? Nesse ponto, o professor elabora algumas hipóteses sobre o conhecimento dos alunos, sobre o que eles sabem, ou não, sobre a matemática que pretende ensinar. 
0 terceiro diz respeito à escolha da tarefa. Van de Walle (2009) menciona que a tarefa não precisa ser muito elaborada, mas a resolução dela deve envolver a matemática pretendida. Antecipar 0 que vai acontecer é o quarto passo mencionado por Van de Walle (2009). Em posse das hipóteses levantadas no segundo passo, agora é o momento de o professor pensar em todas as coisas que os alunos farão quando estiverem trabalhando na tarefa: pensar em como eles podem resolvê-la, quais estratégias podem usar, como os conhecimentos matemáticos serão articulados e identificados, entre outros. 0 ideal seria que outros pesquisadores e professores tivessem a curiosidade de investigar essa tarefa, modificar ou reformular a ideia original, levantando questionamentos que provocassem 0 pensamento de estudantes vinculado aos campos matemáticos em jogo na situação.

\section{FINALIZANDO A CONVERSA}

Neste artigo, nosso objetivo foi identificar conceitos matemáticos que as crianças evidenciaram em seus desenhos, com base no que elas haviam entendido da história lida pela professora. Em primeiro lugar, a tarefa tem potencial para 0 ensino de matemática por meio de resolução de problemas ${ }^{10}$. Integra conceitos de aritmética, álgebra, geometria e apresenta desafios às crianças. 0 enunciado possibilita trabalhar com ideias de quantidade, contagem, correspondência, comparação e sequências recursivas (a mais que, menos de). Podem ser tratadas as noções de medidas relacionadas aos diversos tamanhos e também noções espaciais elementares, envolvendo posicionamento e localização de objetos.

Em segundo lugar, por se tratar de resolução de problemas, concordamos com Polya (1973), quando diz existir a necessidade de interações e questionamentos de professor e alunos e dos alunos entre si. Embora, a professora $\mathrm{C}$ não tenha desenvolvido essa etapa, quando trabalhou o problema com seus alunos, sugerimos que o professor deve pensar em perguntas para fazer a cada turma, a cada nível de ensino ou a cada tipo de problema. No caso específico da tarefa selecionada, as questões referem-se à quantidade $n$ de pássaros que se poderia desenhar [a ser desenhada], ou mesmo sugerindo o posicionamento de árvores, flores e crianças à direita de, à esquerda de ou entre objetos, alterando as quantidades indicadas e verificando as modificações resultantes.

Para que isso aconteça, o professor precisa identificar as potencialidades do enunciado, ter clareza dos conceitos matemáticos envolvidos e identificar quais desses conceitos ele já domina, ou não, para ensinar e desejar aprofundá-los. Precisa também querer interagir com as crianças, tendo por base a resolução de problemas. Ademais, é necessário que planeje cuidadosamente 0 que ${ }^{11} \mathrm{e}$ $\mathrm{Como}^{12}$ vai trabalhar e busque explorar conhecimentos essenciais, para mediar a aprendizagem matemática dos alunos. Enfim, essa análise permitiu-nos verificar que, mediante uma única tarefa, existem diversas possibilidades de ensinar matemática de forma integrada via resolução de problemas, tornando a aprendizagem de conceitos matemáticos um processo prazeroso e significativo.

Essa matemática manifestou-se nos desenhos à medida que estes se constituíram como recurso, como estratégia à resolução de problemas. Observamos que a professora $\mathrm{C}$, a partir das oficinas, começou a sentir-se mais segura em relação ao ensino de matemática e a pensar em tarefas mais

10 Neste texto, optamos por não demarcar a resolução de problemas como meta, processo, habilidade básica (BRANCA, 1997) ou perspectiva metodológica (ONUCHIC; ALLEVATO, 2011), pois consideramos que o problema pode transitar por todas elas, dependendo da intencionalidade pedagógica de cada professor.

110 que ensinar refere-se aos conteúdos matemáticos definidos pelo professor para a aula ou conjunto/sequência de aulas.

120 como ensinar envolve os modos pensados e planejados pelo professor para ensinar os conteúdos matemáticos definidos para a aula ou conjunto/sequência de aulas. Aqui é fundamental que o professor tenha consciência dos conceitos matemáticos que sabe, entende e sabe ensinar e que deseje aprender os conceitos que ainda não entende e não sabe explicar. Ou seja, um professor sabe como ensinar conceitos matemáticos quando possui entendimentos instrumental e relacional desses conceitos como afirmava Skemp (1976). 
criativas. Portanto, mesmo não tendo discutido as potencialidades da tarefa proposta pela professora $\mathrm{C}$ nas oficinas de formação continuada, trazemos aqui para que outros professores percebam a riqueza e a quantidade de assuntos matemáticos e outros que são possíveis de ser trabalhados por meio dela. Chamamos a atenção para que professores observem em suas próprias tarefas, naquelas que planejam na rotina diária, qual a potencialidade matemática de cada uma e como cada tarefa pode ser explorada, para que o conteúdo matemático seja evidenciado. Caso outro professor use uma tarefa similar, deve dispensar um olhar atento aos desenhos que seus alunos farão, para representar a história lida. Além do mais, deve dialogar com eles acerca desses desenhos.

\section{REFERÊNCIAS}

BRANCA, N. A. Resolução de problemas como meta, processo e habilidade básica. In: KRULIK, S.; REYS, R. E. (Org.). A resolução de problemas na matemática escolar. Tradução de Hygino H. Domingues e Olga Corbo. São Paulo: Atual, 1997, p. 4-12.

BRASIL. Ministério da Educação. Base Nacional Comum Curricular (BNCC). Brasília: MEC/CONSEP/UNDIME, 2017.

Parâmetros Curriculares Nacionais: matemática. Ministério da Educação, Secretaria de Educação Fundamental. Brasília: MEC/SEF, 1997.

CHAPMAN, 0. Researching teaching qualitative techniques. Cadernos de Pesquisa em Educação, Vitória, PPGE/CE, UFES, v. 12, n. 23, p. 105-135, jan./jun. 2006.

DINIZ, M. I. Resolução de problemas e comunicação. In: SMOLE, K. S.; DINIZ, M. I. (Orgs.). Ler, escrever e resolver problemas: habilidades básicas para aprender matemática. 1. ed. Porto Alegre: Artmed, 2001, p. 87-97.

ERNEST, P. The impact of beliefs on the teaching of mathematics. In: KEITEL, C.; DAMEROW, P.; BISHOP, A.; GERDES (Eds.). Mathematics, education and society. Paris: United Nations Educational Scientific, 1988, p. 99-101.

ESPÍRITO SANTO. Secretaria da Educação. Currículo Básico Escola Estadual (CBC). Ensino fundamental: anos iniciais. Vitória: SEDU, 2009.

FIORENTINI, D.; LORENZATO, S. Investigação em educação matemática: percursos teóricos e metodológicos. 2. ed. rev. Campinas, SP: Autores Associados, 2007.

FLICK, U. Desenho da pesquisa qualitativa. Porto Alegre: Bookman, 2009.

GÓMEZ-CHACÓN, I. M. Matemática emocional: os afetos na aprendizagem matemática. Tradução de Daisy Vaz de Moraes. Porto Alegre: Artmed, 2003.

HUBERMAN, M. Tendências gerais do ciclo de vida dos professores. In: NÓVOA, A. (Org.). Vida de professores. Porto, Porto Editora, 1993, p. 37-46.

LINS, R. C. Matemática, monstros, significados e educação matemática. In: BICUDO, M. A. V.; BORBA, M. de C. (Orgs.). Educação matemática: pesquisa em movimento. 4. ed. São Paulo: Cortez, 2012, p. 101-131. 
LORENZATO, S. Educação infantil e percepção matemática. 2. ed. rev. e ampliada. Campinas, SP: Autores Associados, 2008.

MORO, M. L. F. Notações na iniciação matemática: a repetição de grandezas na raiz da multiplicação. In: MOR0, M. L. F.; SOARES, M. T. C. (Orgs.). Desenhos, palavras e números: as marcas da matemática na escola. Curitiba: Ed. da UFPR, 2005, p. 41-76.

ONUCHIC, L. de la R. Ensino-aprendizagem de matemática através da resolução de problemas. In: BICUDO, M. A. V. (Org.). Pesquisa em educação matemática: concepções e perspectivas. São Paulo: UNESP, 1999, p. 199- 218.

ONUCHIC, L. de la R.; ALLEVATO, N. S. G. Novas reflexões sobre o ensino-aprendizagem de matemática através da resolução de problemas. In: BICUDO, M. A. V.; BORBA, M. de C. (Orgs.). Educação matemática: pesquisa em movimento. 4. ed. São Paulo: Cortez, 2012, p. 213-231.

Pesquisa em resolução de problemas: caminhos, avanços e novas perspectivas. Bolema. Rio Claro, UNESP, v. 25 , n. 41 , p. $71-98$, dez. 2011.

PIMENTEL, L. S.; LARA, I. C. M. de. Resolução de problemas na educação infantil: uma análise do uso da estrutura multiplicativa. Vidya, v. 35, n. 1, p. 109-120, jan./jun. 2015.

POLYA, G. How to solve it: A new aspect of mathematical method. 2. ed. New Jersey: Princeton University Press, 1973. (A obra foi publicada originalmente em 1945.)

SANTOS, V. M. P. dos. Avaliação de aprendizagem e raciocínio em matemática: métodos alternativos. Rio de Janeiro: Projeto Fundão, Instituto de Matemática da Universidade Federal do Rio de Janeiro, 1997.

SANTOS-WAGNER, V. M. Resolução de problemas em matemática: uma abordagem no processo educativo. Boletim GEPEM, Rio de Janeiro, n. 53, p. 43-74, jul./dez. 2008.

SCHROEDER, T. L.; LESTER JR, F. K. Developing understanding in mathematics via problem solving. In: TRAFTON, P. R.; SHULTE, A. P. (Eds.). New directions for elementary school mathematics. Reston: NCTM, 1989, p. 31-42.

SHULMAN, L. S. Knowledge and teaching: foundations of the new reform. Harward educational review, v. 57, p. 1-22, 1987. Those who understand: knowledge growth in teaching. Educational researcher, v. 15, n. 2, p. 4-14, 1986.

SKEMP, R. Relational understanding and instrumental understanding. Mathematics Teaching, n. 77, p. 20-26, 1976.

SMOLE, K. C. S. A matemática na educação infantil: a teoria das inteligências múltiplas na prática escolar. Porto Alegre: Artmed, 2003.

THOMPSON, A. G. Teachers' beliefs and conceptions: a synthesis of the research. In: GROUWS, D. A. (Ed.), Handbook of research on mathematics teaching and learning. A project of the National Council of Teachers of Mathematics. New York: Macmillan Publishing Company e Reston; VA: National Council of Teachers of Mathematics, 1992, p. 127-146. 
A relação entre concepções de matemática e de ensino de matemática de professores na prática pedagógica. Tradução de Gilberto F. A. de M., Tadeu 0. G., Revisão de Maria Aparecida C. R. T. Moraes e Antônio Miguel. Zetetiké, CEMPEM - FE/UNICAMP, v. 5, n. 8, p. 58-78, jul./dez. 1997. (Esse artigo de Thompson foi publicado originalmente em inglês na revista Educational Studies in Mathematics 15, 1984, p. 105-127.)

VAN DE WALLE, J. A. Planejamento em uma sala de aula baseada em resolução de problemas. In: VAN DE WALLE, J. A. Matemática no ensino fundamental: formação de professores e aplicação em sala de aula. Tradução de Paulo Henrique Colonese. 6. ed. Porto Alegre: Artmed, 2009, p. 82-92.

ZANON, T. X. D. Imagens conceituais de combinatória no ensino superior de matemática. 2019. 332f. Tese (Doutorado em Educação) - Programa de Pós-Graduação em Educação, Universidade Federal do Espírito Santo, Vitória.

Formação continuada de professores que ensinam matemática: 0 que pensam e sentem sobre ensino, aprendizagem e avaliação. 2011. 300 f. Dissertação (Mestrado em Educação) - Programa de Pós-Graduação em Educação, Universidade Federal do Espírito Santo, Vitória.

RECEBIDO EM: 21 jun. 2020

CONCLUÍDO EM: 12 out. 2020 